\title{
Cross-cultural Communication and Foreign Language Teaching
}

\author{
Hu Song \\ School of foreign languages, Dalian Jiaotong University, Dalian, Liaoning, 116021, China
}

Keywords: cross-cultural communication; foreign language teaching

\begin{abstract}
Through researching basic contents of cross-cultural communication, this paper discusses inseparable relationship between cross-cultural communication and foreign language teaching and main problems existing in current foreign language teaching, and points out the fundamental objective of foreign language teaching - to achieve cross-cultural communication.
\end{abstract}

\section{Introduction}

The purpose of studying cross-cultural communication includes three. Firstly, cultivate people to hold active understanding attitude to different cultures. Cultures are different. Through discovering differences of the other party, we can in turn deepen understanding of our culture so as to master cultural features objectively. In the process of discovering differences, we should notice significant the common points. Secondly, cultivate adaptive capacity during cross-cultural contact. When contacting different cultures the first time, we will often suffer cultural shock and thus result in maladjustment. To make communication continue, we must try our best to relieve impacts and improve adaptive capacity. Thirdly, cultivate cross-cultural communication skills. As opening to the outside world further expands, the number of people going abroad or participating in cross-cultural communication domestically becomes more and more. They need to learn and master practical skills when communicating with people from different cultural backgrounds. Based on this, practical significance of study on cross-cultural communication is greater than theoretical significance.

\section{Basic research contents of cross-cultural communication}

Basic research contents of cross-cultural communication include the following: 1) world outlook and values; 2) cultural characteristics of verbal behaviors; 3) non-verbal communication.

World outlook refers to people's fundamental views on the world, including the position of people in the universe, the relationship between human and nature and so on. From the perspective of the relationship between human and nature, oriental and western cultures have completely different views. Western culture considers human beings should dominate nature. Nature is the conquest object of human. Human beings can utilize science and technology to transform nature and conquer nature. Correspondingly, oriental culture thinks human and nature have harmonious relationship. Human and nature are closely related. Human beings should not transform nature, but adapt to nature and utilize conditions of nature to serve for human being.

Value refers to the standards to judge the right and the wrong. It will guide human behaviors. So, value consists of the backbone of culture and social structure. For a person attached to a culture, their behaviors are dominated by the value. Value is an abstract concept. It is difficult for people to grasp it. But the value of a culture can be seen from linguistic or non-linguistic behavior patterns.

Assume a kid sees the fruit tree of the neighbor is filled with apples and does not pick them. If he is asked whether he does not pick the apples, how will he answer? If he is a European or American kid believing in Christianity, he will answer, "I cannot do it, because God looks at me." If he is a Chinese or oriental kid, he will certainly say, "the apples belong to others, we cannot pick them.” In cross-cultural communication process, the value hidden in culture cannot be avoided. People deepen understanding of cross-cultural communication through understanding differences of values. This is because cross-cultural communication will go wrong when different values oppose each other.

As for cultural characteristics of verbal behaviors, this is another important topic of 
cross-cultural communication. Culture has distinct individuality. Different cultures naturally have discrepancies. If cultural differences are reflected in language, they will become linguistic differences. Language is the product of culture and a manifestation pattern of superior culture. Language application must follow culture rules. In other words, culture decides thinking and expression mode of language. We superior culture foreigners learn Chinese. Apart from language knowledge, they must learn the knowledge of Chinese society and culture.

Non-language behaviors and language behaviors are the same. Due to different cultures, there are different meanings. In the process of language behavior, since different vultures have different interpretations of non-language behaviors, misunderstanding often happens. Non-verbal communication is mostly regarded as a pronoun of body language. Actually, its range largely exceeds pure body language. From human body features to their garment accessories, from voice to room furnishing, light and core, and from time concept to space concept. All these are non-verbal communication factors. For example, Japanese bow, occidental embrace and skill as well as raising the hat in salute in Latin America show their cultural features. Of course, non- language information may easily lead to misunderstanding and sometimes even result in tragedies.

\section{Cross-cultural communication and foreign language teaching}

Cross-cultural communication and foreign language teaching are inseparable. This is because foreign language teaching aims to not just impart language knowledge, but also to cultivate students' communicative competence and cross-cultural communication skills. In this sense, it is more appropriate to regard foreign language teaching as a part of cross-cultural education. As early as the middle of 1980s, college English education in China formulated teaching program uniformly. CET-4 and CET-6 were carried out in late 1980s. All these propose higher requirements for English application ability of college students. However, universal exam-oriented education gives rise to quite large negative effects. Besides, traditional foreign language education concept also deeply constrains us. From the primary school, Chinese students will learn English for more than 10 years. Their most time and energy are spent in looking up words in the dictionary, remembering words and analyzing sentence pattern. They can easily deal with examinations, but often have many problems in cross-cultural communication.

\section{IV problems in foreign language teaching}

There are mainly three problems in foreign language teaching:

Problem 1: regard learning language and vocabulary as the whole of foreign language learning. In this way, students have poor ability to send out information and gain information and their comprehensive communicative competence is also poor.

Problem 2: learning method is old and only a part is seen. Influenced by traditional study of Chinese characters, students keep on the rails to learn foreign language. They often focus on comprehension of words and sentences, and rarely notice articles. They often value information reception and neglect information sending.

Problem 3: comprehensive language ability is strong, but cross-cultural comprehension is poor. There is lack of social skills. When language competence improves to a level, cultural barriers stand out. Language faults may easily gain others' understanding, but pragmatic failure and cultural misunderstanding will often lead to contradictions and even communication failure. A person who is proficient in speaking a foreign language often hides a cultural hypothesis so that people will wrongly consider he also own cultural background and values of such language. His pragmatic failure sometimes will make one suspect this is a deliberate verbal behavior, thus leading to conflicts.

In China, people do not well cognize the importance of cross-cultural understanding. A large number of people consider this is just a matter of learning a foreign language. However, a common sense behavior in Chinese cultural background may become a non-common sense behavior in a foreign background. Some consider cross-cultural communication is equal to the abilities to listen, 
speak, read and write. These four abilities are important and the foundation of cross-cultural communication. But they are not the whole of problems. Language is a product of culture. It owns profound cultural connotation. How to express thoughts for different objects is related to cultural background.

\section{Conclusions}

The fundamental objective of foreign language teaching is to fulfill cross-cultural communication and communicate with people with different backgrounds. Comprehensively improving efficiency and quality of foreign language teaching and largely boosting students' foreign language application ability are urgent needs of China's national economic development and urgent tasks of Chinese higher education. To achieve this objective, we need to correctly cognize foreign language education is a part of cross-cultural education. Foreign language teaching should closely approach development direction of world education and make constant efforts to cultivate talents with cross-cultural communication.

\section{References:}

[1] Birdwhistell, Ray. Kinesics and Context. Philadelhia: University of Pennsylvania Press. 1970.

[2] Cen Jianjun, today's difficulties will greatly contribute to later generations [J]. Research of Teaching and Teaching Materials. 1977 (2)

[3] Chen Zufu, Meet era challenges and update educational thought and ideas. Research of Teaching and Teaching Materials. 1977 (3) 